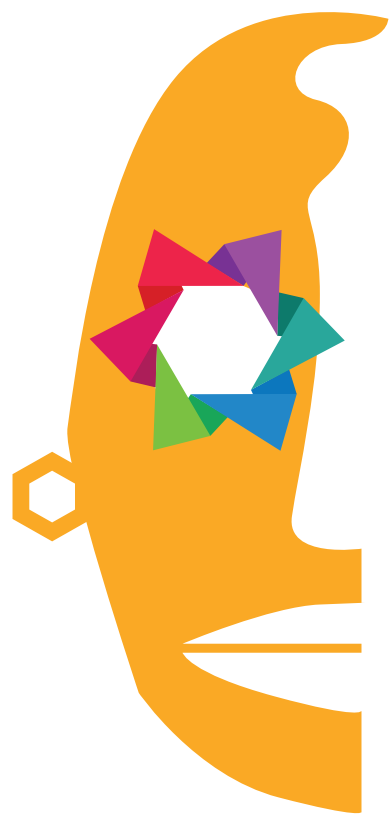

\section{Claudia Caisso}

Universidad Nacional de Rosario Argentina

\section{El Caribe como espejo y descentramiento en la} poética de Derek Walcott

\section{Resumen}

El trabajo analiza la integración y proyección del Caribe que Derek Walcott construyó a través de puentes analógicos y la traslación del imaginario del libro-archivo al paisaje en Las Antillas, fragmentos de una memoria épica (1992). Por otra parte, se detiene en la valoración que el autor de Omeros (1990) hizo de la imitación como una matriz intercultural decisiva en El Caribe. ¿cultura o mimetismo? (1974). Destaca posiciones teóricas construidas en el ensayo a partir del cuestionamiento de hipótesis propuestas por Vidia Naipaul en Los simuladores (1967) y considera la relevancia alcanzada por las manifestaciones de la relación especular en la vida antropológica de la región. Por último, describe la articulación intertextual que existe entre aquel proceso y representaciones trazadas en Cuaderno de un retorno al país natal (1939) de Aimé Césaire, por medio de la cual se interpela la creencia en la originalidad cultural y el eurocentrismo.

Palabras clave: Caribe anglófono, Poética de Derek Walcott, interculturalidad, creolización, pensamiento descolonial
Abstract
The work analyzes the integration and projection of the Caribbean that Derek Walcott constructed through analogical bridges and the translation of the imaginary of the book-archive to the landscape in The Antilles, fragments of an epic memory (1992). On the other hand, it stops at the evaluation that the author of Omeros (1990) made of imitation as a decisive intercultural matrix in The Caribbean. Culture or mimicry? (1974). It emphasizes theoretical positions constructed in the essay based on the questioning of hypotheses proposed by Vidia Naipaul in The Mimic Men (1967) and considers the relevance achie- ved by the manifestations of the specular relationship in the region 
anthropological life. Finally it describes the intertextual articulation that exists between that process and the representations drawn in Aimé Césaire's Cahier d'un retour au pays natal (1939) by means of which the belief in the cultural originality and the Eurocentrism are questioned.

Keywords: Anglophone Caribbean, Poetics of Derek Walcott, interculturality, creolization, decolonial thought

\section{Introducción}

No parece ocioso señalar con Bruce King, destacado biógrafo e historiador del momento de emergencia y evolución del teatro walcottiano, que la proyección que Derek Walcott alcanzó más allá del Caribe se ha sostenido, entre otros motivos, por la labor de creación casi titánica de una compañía de actores para la región y producción de una vasta serie de obras teatrales (King, 2004). Entre esos trabajos se encuentra la célebre obra Sueño en la montaña del mono que durante varios años emblematizó la labor del T.T.W. (Trinidad Theater Workshop) con base en Puerto España y que usaba como ícono de presentación en las giras, la fotografía del rostro del actor Errol Jones. En tal búsqueda se han condensado cuestiones axiales de la experiencia histórico-cultural caribeña al tiempo que se desplegaba un campo plural de experimentación: la exploración de las posibilidades que ofrecía una nueva concepción del espacio, la reconfiguración del cuerpo anclado en el color de la piel, la inscripción del trauma impuesto por la fundación de la trata, la puesta en situación a través de la danza, la intervención de rituales inspirados en prácticas religiosas y el insistente contrapunto entre el inglés y el "patois". Matrices que para ser procesadas necesitaron la creación de un laboratorio situado con que trascender el teatro naturalista y las apuestas vanguardistas europeas. Según puede leerse en las casi oraculares líneas del ensayo La voz del crepúsculo (1970) que ofició de prólogo a la edición de cuatro obras teatrales walcottianas donde se relata el proceso de creación del T.T.W. (Caisso, 2015) y la búsqueda de un lenguaje genuino con el que tomar la palabra. En ese marco, el llamado teatro del absurdo, el teatro de la pobreza y las tentativas de Artaud, estaban destinados a traducir el deseo de expiación de la culpa experimentada por Europa a consecuencia de los genocidios perpetrados, pero no alcanzaban a representar cabalmente la experiencia plural del Caribe (Walcott, 2000).

Contra aquel telón de fondo, la escritura en prosa con intervenciones de variado estatuto que el autor santalucense sostuvo a lo largo de su vida, constituye uno de los más vigorosos pilares de una prolongada construcción. Puesto que es en sus ensayos donde se pueden reconocer las marcas de la búsqueda que, tanto en Inglaterra como en EE.UU., sostuvo Walcott para ser reconocido como escritor. Pero, además, es posible encontrar allí la descripción de estrategias de creación de un lugar diferente para la ficción distanciándose, mezclando y reinventando 
ideologías estéticas con posicionamientos que implican profundas operaciones selectivas y nuevos entrecruzamientos de la tradición cultural caribeña con la europea y la americana.

El crítico jamaiquino Edward Baugh, avezado lector de Walcott, en The West Indian Writer and his Quarrel with History (2012), artículo que merece ser considerado un clásico en los estudios de la literatura del Caribe anglófono, afirma que el escritor santalucense debe ser concebido como uno de los más lúcidos creadores de la región. Para potenciar tal afirmación, le hace compartir tal escena de reconocimiento junto a otros escritores de su generación tales como el narrador Wilson Harris de la Guyana británica, el narrador George Lamming y el poeta Kamau Brathwaite de Barbados. Para el crítico jamaiquino son prácticamente los únicos que cuentan con capacidad para teorizar. Una singular habilidad para pensar, describir e interrogar qué están haciendo y para qué. No se trataría según Baugh (2012) de un fenómeno en el que es posible reconocer un talento particular para programar la producción de una obra o trazar cierto horizonte más o menos constante de los avatares de una poética, sino más bien, de la capacidad para reflexionar acerca del trayecto realizado articulándolo con otras producciones. De tal manera que la habilidad para argumentar enciende la construcción de una mirada generacional que pone en contexto tensiones constitutivas de diversas poéticas a la luz de las tensiones reconocibles a nivel de la experiencia social y en los usos de diversas prácticas culturales, saberes, límites y potencialidades con que cuentan las culturas de pertenencia.

En 1992, con motivo de la recepción del Premio Nobel y a posteriori de la aparición de Omeros (1990), obra que marcaría el final de la fase odiseica en la poética walcottiana, Walcott traduciría en Las Antillas: fragmentos de una memoria épica (2000), el destino de su labor en términos de una encendida defensa del medioambiente y de la celebración del Caribe como espacio dado a la "convivialidad" o a la coexistencia interracial e interlinguística. A tal punto que es posible señalar que tal defensa del mestizaje con el que se cuestiona el racismo y se elogia el cuidado del medioambiente, retoma cuestiones recurrentes en sus trabajos, forjando el asiento constante de una intervención crítica ante la Modernidad. Puesto que la defensa de la coexistencia interracial e interlingüística retoma el tema de la desconfianza en el progreso: vuelve a ceñir y despliega la imagen por la cual el progreso es una ilusión sostenida por el discurso de la historia como pesadilla. Walcott invocaría en reiteradas oportunidades aquella "epifanía" joyceana para usarla en su argumentación enlazándola con el mito del arte y la fuerza transmutativa que les asignó a las lenguas locales de origen africano en relación con las lenguas metropolitanas. Impulso sobre el que reflexionó focalizándose en el acto de pasaje del Dante como poeta sensiblemente atento a la local intensidad de la 
lengua vernácula cuando registra el momento auspicioso del nacimiento del toscano: una lengua emergente mediante la cual se interpela y trasciende una lengua más extendida, momificada e imperial como el latín. Alentado por la rememoración de aquel duelo de la escritura dantesca (Fumagalli, 2001) y por la revalorización de los "modernos clásicos" a la que lo condujeron en particular las lecturas de Pound y Eliot, el escritor santalucense volverá más de una vez a la capacidad del creole para descastar la fijeza de los museos, la supuesta superioridad de las lenguas metropolitanas y los academicismos pétreos (Walcott, 2000).

Líneas de fuerza que sostienen la lectura del Caribe como un espacio vivificante, capaz de albergar una ciudad bordeada por una naturaleza no torturada que, en tanto tal y según se lee en el discurso que estamos comentando, constituye una ciudad utópica. Esto es: un territorio que no ha sido todavía fagocitado por el automatismo de las máquinas y donde todavía se expresa la cifra de fuertes impulsos de relación del presente con el pasado. Así Puerto España aparece comparada con Atenas en el paso de un recurso insistente que abre, como en otros momentos de la obra, el favor del puente analógico: la apelación al vínculo especular que pone al Caribe en relación con el registro material de otras culturas en otras latitudes, antes que con la posibilidad de fetichizar el pasado poblado de episodios que realmente sucedieron o buscar un origen. Al Caribe, por el contrario, se lo "relaciona" insistentemente y, como en muchos momentos de la poética walcottiana, se lo compara con Grecia, analogía que genera como efecto el imaginario del Nuevo Egeo, pero también con Egipto, el lejano Oriente, la India o Irlanda. En una trama relacional que, como también ocurre en la escritura poética de Walcott, parece portar el ojo de una cámara cinematográfica cuya capacidad escópica o habilidad para perspectivizar la mirada, genera un relato que cuenta con un poder extraordinariamente amplio en la captación de seres y cosas, el ritmo de la nominación, la enumeración y los desplazamientos de un lugar a otro ${ }^{1}$.

En ese marco, pasar de un lado a otro las huellas que ofrece la percepción visual, comparar para exaltar, concederle fulgor al detalle y los restos vestigiales se constituye en un gesto primordial por medio del cual conferirle valor a lo propio. Puerto España es comparada con la Dublín de Joyce y Atenas, ciudades de la experiencia, telares de la memoria, donde el eco o la mera repetición son atravesados para que irrumpa la productiva cantera que, según el poeta, se ofrece

1 Por otra parte, es necesario destacar, además, que varias de las relaciones dibujadas en Las Antillas... (2000) afirman el reconocimiento de la cultura hindú como una vía estratégica para revertir el odio interracial que la colonialidad le impuso al Caribe anglófono con la suplantación de los trabajadores afrodescendientes por los "coolíes" o "indian identured labourers". Colectivos diasporizados que fueron usados para servir como mano de obra contratada después de que fuera prohibida la esclavitud y declarada su abolición en 1838 como efecto de las fuertes presiones que las sucesivas rebeliones esclavas impusieron sobre el parlamento inglés, por un lado, y por la defensa del libre comercio que comenzó a asumir por razones económicas Gran Bretaña, por otro lado (James, 2010). 
en algunos lugares como una maraña babélica de lenguas. La ciudad funciona así como una cita comprimida de un espacio más vasto como el Caribe y, este a su vez, como un archivo que se contrae, se expande y se proyecta a la luz de una multitud de juegos entre autores, libros, máscaras, rituales y espejos.

¿Cómo no recordar, en tal sentido, que para el poeta la "bastardía del estilo" (Walcott, 2000, p. 20) hace señas sobre el deseo subjetivo y de su generación de sostener la misión integradora que señala en el ensayo "La voz del crepúsculo" y se materializa en el acto de "purificar la lengua de la tribu"?, y ¿cómo no destacar, además, que la base de esa lengua de la tribu es concebida positivamente en tanto y en cuanto se trata de una lengua babélica? El Caribe para Walcott expone su potencialidad cada vez que es posible reconocer que se habita un espacio donde conviven una multitud de lenguas, ruidos y ecos que el poeta deslíe para rearticular los hilos de un tejido abigarrado y denso que contará con nuevos sentidos. Puesto que es ese caos el que emplaza el derecho a nacer de nuevo cuando ese derecho se parece a la posibilidad de volver a leer y a nombrar, cambiando los soportes materiales de la escritura y trasladando el imaginario del libro-archivo, tanto más poderoso en virtud de la traumática experiencia de las poblaciones africanas esclavizadas. En un movimiento de reivindicación de la memoria que acontece más allá de la escritura o de la dimensión canónica que Occidente le asigna a la cultura letrada y por lo cual a veces se enuncia que "El mar es la Historia", un espacio surcado por "el Éxodo/Hueso soldado por el coral hueso" (Walcott, 1996, p. 67) en abierta alusión al pasado del Caribe como Middle Passage o Pasaje del Medio, en el que el paisaje del fondo del mar registra las marcas del genocidio y se transforma en archivo de la memoria africana ${ }^{2}$. Escena que requiere ser considerada como una matriz simbólica constitutiva de las literaturas de la región y que, antes que Walcott, fue excavada por Césaire en el célebre Cuaderno de un retorno al país natal (1939), texto en el que las imágenes poéticas estratégicamente abren la relación entre el color rojo de las flores y la inscripción de la sangre derramada: un mapa donde interviene la fecunda interacción entre el testimonio que todavía ofrece el entorno natural y los mártires que ya no atestiguan (Césaire, 2000).

Otras veces en la poética walcottiana las hojas de los árboles producen sonidos que equivalen a los de una lengua nativa como la que genera el fluir de las aguas, "que están ahí para ser leídas y si se las lee correctamente crean su propia literatura" (Walcott, 2000, p. 106). O bien el Caribe se asemeja a un libro de libros

2 Idéntica construcción reivindicativa del archivo del paisaje se encuentra cuando se lee "No se trata de que la Historia quede borrada por este amanecer. Sigue estando allí, en la geografía antillana, en la propia vegetación. El mar suspira con los ahogados desde que comenzó el tra'fico de esclavos a través del Atlántico, con la matanza de sus aborígenes, caribe, arahuaco y taíno, sangra en el escarlata de la siempreviva, y $\mathrm{ni}$ siquiera la acción de las olas sobre la arena puede borrar la memoria africana'"' (Walcott, 2000, p. 105). La cursiva es nuestra. 
"donde las páginas del mar, /son un libro que un maestro ausente dejó abierto/ en mitad de otra vida" (Walcott, 2017, p. 91). En el acto de re-inscribir que implica la posibilidad de trasladar de un lado a otro el imaginario del libro como archivo hacia otras materialidades y experiencias se desplazan, descentran y transgreden interpretaciones que configuran férreamente ciertos imaginarios coloniales: la escritura presenta un proceso interactivo nuevo por el cual se potencia el lugar de la memoria africana. En esa misma dirección la ciudad puede ser advertida como un espacio habitable en tanto y en cuanto la polis simboliza el sitio donde la cultura es capaz de volver a comenzar según dice Walcott (2000) y donde la poesía se hace visible, esto es, reagrupa los fragmentos y los erotiza en una serie de quehaceres que admiten ser interpretados en términos de supervivencia.

\section{Reinvención de la memoria y defensa de la diversidad}

La isla irrumpe en virtud de un espacio mayor que carece de originalidad, una geografía situada pero en serie, fragmento del archipiélago, donde acontece un juego de contrapuntos entre textos canónicos y performances, relaciones y proyecciones, en la construcción de un espacio que, antes que materializarse en el enfrentamiento con el Otro europeo o americano, deviene linde, borde poroso y ampliación de las fronteras. Se trata del lugar donde se accede al acontecimiento adánico de volver a nombrar cada día como si fuera la primera vez y de un nacer siempre recomenzado de un pueblo y una lengua nueva (Walcott, 2000). En esa convivialidad, los sitios habitados son concebidos como una "ciudad variada en su composición racial, de tal modo que en ella estuviesen representadas todas las culturas del mundo -la asiática, la mediterránea, la europea, la africana-" (Walcott, 2000, pp. 97-98), ejercicio de resguardo de matrices fuertes de defensa de la diversidad cultural que se presenta como una huella nuclear del Caribe y es sostenida, además, por otros talentosos creadores de la región.

Walcott (2000) traza la utopía de la polis, la serie de aspectos que conforman una ciudad ideal, según dice, porque puede reconocer allí algo de la dimensión humana no mancillada, cada vez que ese espacio se manifiesta como una cita diferida de un fenómeno más extendido en el tiempo y el espacio: la feria donde se escuchan varias lenguas de afrodescendientes, de europeos y de indígenas (caribe, arahuaco y taíno). Coexistencia lingüística y racial, que constituye una de las claves positivas que guían durante una amplia brecha temporal su trayecto imaginativo y crítico respecto de las morales de consumo y la superficialidad impuesta por las industrias del turismo. Puesto que es posible afirmar que cuando Walcott señala el destino de la escritura de ficción, son aquellos valores los que sitúan algunos de los núcleos más persistentes de su trabajo, mientras se afirma la importancia del nacimiento de una literatura -según dice- que produce una nueva memoria capaz de cuestionar y relativizar numerosas estrategias de fortalecimiento de los 
poderes hegemónicos. Como ocurre en Las Antillas... (2000) a propósito de la imagen del rocío que hace referencia a los dialectos que se escuchan en el Caribe a contracorriente de "la lengua de Ozymandias", emblema de la lengua imperial. La "lengua de Ozymandias" mencionada en un largo párrafo del ensayo remite al célebre soneto del poeta romántico inglés Shelley, cuyo título es precisamente el apodo de Ramsés el Grande, faraón de la decimonovena dinastía del antiguo Egipto. En el poema Shelley nombra la estatua caída y despedazada del "rey de reyes" hallada por un viajero para abordar la inevitable decadencia de todos los líderes y los imperios. Esa representación y la constelación que abre en el discurso de Walcott es usada para cuestionar un concepto imperial del lenguaje y la defensa tantas veces naturalizada de la superioridad de una lengua o una cultura sobre las otras, así como también los variados mecanismos autoritarios que intervienen en la búsqueda, para él ilusoria, de preservación de poder para el inglés concebido como lengua eterna e incorruptible. Es, entonces, el rocío del dialecto que entra en sutil diferenciación respecto de la estatua de Ozymandias, el que abre el juego de una interacción que para nuestro autor es grata y ha sido destacada en varios momentos reflexivos para afirmar la ductilidad del "patois" - palabra usada insistentemente por Walcott- frente a los efectos innegables de una globalidad totalitaria representada en la fijeza marmórea que patentiza morales de conservación. El créole aparece así reivindicado como fuerza dislocadora de tradiciones porque impulsa su dimensión lozana y renovable frente a la figura de Ozymandias. Entre la dimensión marmórea de "la lengua de Ozymandyas" (Walcott, 2000, p. 93) y la espontaneidad y frescura que ofrecen las lenguas vernaculares -contrapunto que precisa asumir un artista antillano para convertirse en portador de un mensaje integrador-, Walcott abre la descripción del Caribe como un territorio que habiendo nacido de un continente original no admite ser concebido como mera continuidad de otro. Al tiempo que reflexiona, una vez más, acerca de cuestiones que, descentradas y fractalmente localizadas, permiten nombrar y habitar una experiencia que ha permanecido oculta porque ha sido excluida en ciertos usos del relato, tales como los de la historiografía de James Anthony Froude y las crónicas de viajeros victorianos que fijaron para el Caribe los imaginarios de falta de cultura, ilegitimidad y desarraigo (Walcott, 2000).

Así el Caribe walcottiano se dibuja en la larga etapa conocida como fase odiseica como un espacio geopolíticamente localizado pero descentrado. Es en la energía que Walcott releva a propósito del impulso adánico que el lugar deviene morada de alegorías del porvenir por las cuales nombrar implica inventar el mundo cada mañana y donde tanto los restos de lo perdido como la falta de monumentos y bibliotecas, se invisten con las fuerzas de una singular promesa (Walcott, 2000). De allí la representación del Caribe como un vaso roto cuyas partes o fragmentos remiten al desvío de la épica y al paso con que se afirma que la "sublime estupidez" 
que es la poesía, no cesa de reunir en su impulso erótico aquello que ha padecido la violencia aniquiladora. Ese impulso libidinal que alcanza a formular una "estética de los fragmentos" es capaz de erotizar lo siniestro y lleva a formular un gesto relativizador de la fe generada por algunos usos unívocos de la historiografía, de tal modo que es la poesía la que puede enamorarse nuevamente del mundo -según se lee- a pesar de la Historia (Walcott, 2000, p. 103). En ese marco, la "sublime estupidez" del poema concentra los juegos de la gracia y apuesta al poder del lenguaje que cobra aliento en el uso de mitos arahuacos, griegos y africanos, mientras prueba la lanzadera de la desmitificación puesto que se trata de un mar donde los dioses han caído, según se lee en las primeras páginas de Omeros.

Las Antillas... (2000) formula así una intervención que aspira a integrar el mundo de los afrodescendientes con el de los coolíes y, al mismo tiempo, aspira a recordar la relación especular que ese espacio encuentra con otras latitudes. Gesto que Walcott articuló como una genuina matriz compositiva. En una búsqueda de puentes analógicos que lo invitan a nombrar el valor de la copia y la existencia de espejos para proponer otros derroteros. Para el autor, el Caribe lejos de ser original, espejea otros mundos, los repite y recrea. Uno de esos espejos, como ya ha sido señalado es el mar Egeo que funciona como una suerte de motor inquieto por el que se desatan valiosos "paseos de la imaginación" a lo largo de un vasto movimiento compositivo que es posible establecer desde sus Poemas selectos publicados en 1964 hasta Omeros publicado en 1990. Es interesante recordar, por otra parte, que no fue Walcott quien produjo la emergencia de aquella analogía, sino más bien quien se encargó de transformarla. Puesto que esa comparación ya había aparecido en algunos discursos históricos ingleses del siglo XIX, entre otros, en Los ingleses en las Indias Occidentales o el escudo de Ulises de James Anthony Froude, autor que Walcott menciona en más de una oportunidad en Las Antillas, fragmentos de una memoria épica (2000). El texto de Froude apelaba a la comparación entre el Caribe y el Egeo para exaltar las destrezas épicas de la fuerza naval británica y legitimar la empresa colonial británica, perspectiva que Walcott descentró e interpeló.

\section{Más acá y más allá del espejo: el mimetismo revalorizado}

18 años antes de la recepción del Nobel, en la presentación El Caribe. ¿cultura o mimetismo? (2016) elaborada para participar en la Asamblea Americana sobre los Estados Unidos y el Caribe que se realizó en la Universidad de Miami, Walcott (2016) separaba abiertamente los ámbitos del poder y la cultura para relativizar al primero. En un gesto diplomático que enlazaba al Caribe con el espacio estadounidense mediante la valoración del rol que la cultura negra cumplía en aquel país, afirmaba un paso marcado por el reconocimiento de la autoridad intelectual de varios escritores caribeños. Entre los explícitamente mencionados, aparecen Césaire 
y Fanon, a quienes considera "West Indians" o indoccidentales junto a Garvey, Padmore y Stokely (Walcott, 2016, p. 292). Una serie de líderes afrodescendientes cuyo denominador común era la militancia panafricanista y cuya aptitud política el escritor santalucense reconocía a nivel de la capacidad para sostener acciones en función de la habilidad que demostraban para hacer distinciones.

El ensayo se abre con una escena de neutralización de la autoridad imperial norteamericana que en realidad podría ser considerada una relativización de la autoridad moral del país que, según dice el poeta, es benigno económicamente, pero maligno políticamente (Walcott, 2016). Walcott (2016) abría el reconocimiento del pilar negro de aquella cultura, nacido de la experiencia laboral en la plantación, el gueto y el hábitat ribereño y presente, según señala, en el estilo de vida, el trabajo, el discurso y la música norteamericana. Después de asumir que el planeta ha sido atravesado durante siglos por lógicas coloniales impuestas en el Caribe (la "sombra" del imperio americano y la "sombra" del británico), desplegaba una serie de actos de diferenciación para emplazar la distensión del lugar de la víctima y anular el horizonte de la venganza. Dibujaba un trayecto con el que relativizar los efectos de la hegemonía política y potenciar la energía espiritual con que la cultura afro-americana en particular, exponía su habilidad para automodelarse. En su argumentación no importa quién gobierna, según dice, porque en cultura es imposible fetichizar la supremacía (Walcott, 2016) en una reflexión que lo acerca a la vasta tradición del pensamiento latinoamericano y caribeño que destaca los procesos de transculturación poscoloniales. Más adelante, comparará, además, la singular capacidad de supervivencia de la cultura afrocaribeña en comparación con la indígena desaparecida por el "proceso de defoliación imperialista" europeo que produjo desobediencia y un "proceso genocida (...) que destruyó al hombre originario, destruyó al azteca, al indio americano, y al indio del Caribe" (Walcott, 2016, p. 297), pero que, sin embargo, no pudo destruir al afro-americano.

Entre las figuras no reconocidas expresamente de intelectuales caribeños que constituyen importantes antecedentes en la reflexión es necesario destacar la figura de George Lamming, quien se estableció en Norteamérica en 1956, y en cuyos ensayos literarios reunidos en el volumen Los placeres del exilio de 1960, aparecen varias entradas dedicadas a celebrar el brío creativo de Cyril Lionel Robert James ${ }^{3}$, defensor del mundo de Calibán frente al de Próspero, genuino maestro, notable historiador y un "colón caribeño a la inversa" (Lamming, 2010, p. 252). No son pocos los temas y problemas que circulan entre la escritura del

3 C. L. R. James fue un militante sindical, panafricanista y periodista deportivo de imaginación radical que fue, además, uno de los más notables historiadores marxistas del Caribe anglófono, autor del libro The black jacobins (1938) donde se narra el proceso de la revolución haitiana, quien escribió, además, Mariners, Renegades and Castaways The Story of Herman Meville and the World We live in (1953) mientras permaneció preso en la isla de Ellis, víctima del macartismo durante su estancia en EEUU. 
autor de la novela En el castillo de mi piel (1953) y la escritura de Walcott ${ }^{4}$. De hecho es necesario recordar que si la afirmación que hace Walcott (2016) respecto de que los caribeños indo-occidentales fueron americanos antes que británicos, se asienta en la idea desplegada en el artículo por la cual se sostiene que una cultura irrumpe en relación con el entorno natural y compone una geografía que por obvias razones espaciales hace de los caribeños vecinos legítimos de los estadounidenses, también se asienta plenamente en articulaciones imaginativas que antes fueron proyectadas por escritores como George Lamming. Puesto que cuando Lamming aborda en Los placeres del exilio (1960) el análisis de algunas cuestiones que interesaban a James, en particular la profunda consideración que le dispensaba a la novela Moby Dick de Melville que motivó la escritura de Marineros, renegados y náufragos de 1953 para interrogar el lugar del intelectual en el mundo contemporáneo y la relación entre la novela y el capitalismo, el escritor barbadense puebla la geografía y las apreciaciones del campo intelectual con representaciones fuertemente ancladas en la ficción literaria. De tal modo que trabaja con la figura del personaje Ismael en Melville para argumentar sobre la singularidad del pensamiento marinero de James que, según Lamming, no fue un náufrago ni un renegado, sino más bien el escritor inquieto que había producido un genuino pensamiento deconstructor de la reproducción mecánica de valoraciones coloniales desde La tempestad de Shakespeare en adelante. Y que, de acuerdo a Lamming, además, estaba destinado a excavar eficazmente un camino emancipatorio para los antillanos. Así en el capítulo "Ismael en casa" en Los placeres del exilio (2010) se insistirá en abundantes descripciones del pensamiento de James en relación con la capacidad que el genio, según se dice, muestra frente a la fuerza hasta ofrecer un mapa de la morada caribeña como reverso de las condiciones de sometimiento y hostilidad impuestas por la colonialidad.

Las Antillas -escribe- tienen suerte de estar donde están: al lado de los Estados Unidos, no los Estados Unidos de la línea Mason-Dixon ${ }^{5}$ o las políticas colonizadoras disfrazadas de libertad y autodefensa, no los Estados Unidos que temen las posibilidades de su propia fuerza. Son unos Estados Unidos diferentes que las Antillas pueden explorar. Es el que comenzó en la matriz de una promesa, el que

4 Lamming reconoció que el título de su novela había surgido de una línea de un poema de Walcott incluído en el libro In a Green Night. Por otra parte, es posible ilustrar el influjo de Walcott en Lamming a partir de varias anotaciones que hace el barbadense a propósito de la colonialidad desplegada por la historiografía de James Anthony Froude y de las perspectivas del viajero A. Trollope en "Conflicto e ilusión” (2010, p. 158).

5 Lamming usa la imagen de la "línea Mason-Dixon" para realzar el establecimiento de una frontera de demarcación entre Pensilvania, Virginia Occidental, Delaware y Maryland, cuando esos territorios eran todavía colonias británicas. Cuando Pensilvania comienza a abolir la esclavitud en 1781 comenzó a ser una línea demarcatoria entre estados abolicionistas y no-abolicionistas y permanece después a nivel del lenguaje popular como símbolo de la frontera cultural que separa al Norte con el Sur de los EE.UU. En términos generales podría leerse la evocación de Lamming como un símbolo de las políticas estadounidense que defienden la idea de frontera dura. 
comenzó como una alternativa al Próspero viejo y privilegiado, demasiado viejo y demasiado privilegiado para prestar atención a las necesidades de sus propios Calibanes autóctonos. En el Caribe no somos más que picos de islas, pero nuestro contenido humano porta un paralelo sorprendente con la expectativa que dio origen a los Estados Unidos en el resultado, si no en el método, de su asentamiento temprano (Lamming, 2010, p. 251).

De tal manera Lamming (2010) ofrecía la idea de un país compuesto por varias naciones y proponía que los caribeños tenían derecho a hacerlo propio, entendiendo que era posible transgredir el destino de los EE.UU. reducido a políticas de fuerza sostenidas por el mandato de fronteras duras. Por lo antes expuesto, es posible señalar que varias de las consideraciones walcottianas vuelven sobre aquellos registros cuando trabajan en El Caribe. ¿cultura o mimetismo? (2016) con la ampliación de las fronteras entre el caribeño y el estadounidense. El escritor santalucense cuestionaba algunos efectos políticos de las decisiones tomadas por los EE.UU. y se preguntaba con un dejo de meditada ironía si los caribeños debían sentirse tan americanos como habían tenido que sentirse británicos (Walcott, 2016, p. 291). La reflexión sobre el estatuto cultural del Caribe, partía entonces de la asunción de la falta de soberanía política real del área y del reconocimiento de la fragmentación de la región en virtud de proyectos políticos que apuntalaban el objetivo de erigir nuevas naciones. Walcott se mostraba proclive a defender allí el estatuto archipelágico del Caribe y al Caribe como un espacio abierto a la relación con otras latitudes antes que a la defensa de las islas como estados nacionales. Su advertencia hacía señas, sin extenderse demasiado, sobre el intento fallido de autonomización impulsado por la creación de la Federación de las Indias Occidentales, asociación de colonias británicas que existió entre 1958 y 1962 y fue disuelta cuando Jamaica y Trinidad deciden tomar por cuenta propia las negociaciones con Inglaterra, separándose del resto de las islas e "independizándose" antes que otros espacios insulares tales como Antigua y Barbuda, Barbados, Dominica, Granada, Monserrat, San Cristóbal y Nieves (incluyendo Anguila), Santa Lucía, San Vicente y Granadinas.

Más allá de aquellas huellas de índole histórico-político, a contracorriente de lo que una lectura superficial podría interpretar en términos de un mero gesto de asimilación, el texto se distanciaba de posiciones ciegamente integradoras y tomaba en cambio como nudo gordiano de especulación la evaluación de la imitación. Volvía sobre la tendencia del caribeño a copiar que había funcionado como una fuerte matriz compositiva en la novela Los simuladores (1967) del escritor trinitense Vidia Naipaul. Varios años antes, además, había sido tratada profundamente en el pensamiento decolonial caribeño a poco que se recuerden las brillantes intervenciones de Césaire, Fanon y Glissant, a propósito de los efectos traumáticos 
que la identificación del caribeño con el europeo generaba como marca de la "herida colonial" (Césaire, 1939; Fanon, 1986; Glissant, 2003). Walcott se encontraba abordando nuevamente una tensión nuclear en la reflexión y la ficción caribeña sobre la identidad: la tensión entre cultura e imitación. Lo hacía revisando la práctica del espejeo como una operación estratégica: abriendo diferencias entre los caribeños y el llamado primer mundo integrado por Europa y los Estados Unidos. Entre esas diferencias comprendía la visión política del caribeño reducida a lo esencial y sin ningún anhelo de ejercer hegemonía sobre otras culturas, por lo que afirmaría la dimensión de frontera a un tiempo irreductible y porosa del Caribe. Contra el telón de fondo de los espacios insulares y territoriales que a nivel mundial imponen su hegemonía, el Caribe es dibujado como un espacio capaz de proyectarse culturalmente sin anhelo de imponer hegemonía. En el marco de una mirada que implica relativizar el lugar del Amo, enuncia el aporte del mundo negro en la sociedad norteamericana y el valor de los juegos engendrados por la copia intercultural. El mimetismo es considerado así una de las líneas de fuerza de la vida natural, donde es posible reconocer estrategias de supervivencia mediante la creación de efectos de diseño, señuelo y camuflaje defensivo sostenidos por la producción del semblanteo de diferentes especies de animales que comprenden desde las conductas del "parrotismo" que serían típicas de los loros hasta las variadas gesticulaciones imitativas del mono. Pero también es considerado, además, como principio activo de la resistencia a nivel de la vida antropológica mediante la observación de un ritual clave de la cultura caribeña, como lo es el carnaval de Trinidad. Puesto que Walcott reconoce en esa práctica cultural popular una política de la imitación que es liberadora en tanto y en cuanto es capaz de levantar las vallas de la prohibición, cada vez que los sonidos del "steel-pan" imitaron a los del tambor mientras este último estuvo prohibido y esa imitación, como la desplegada por los disfraces y ritmos usados por el "calypso" desbordan el modelo. Tal reconocimiento, a su vez, implica abrir una profunda operación de descentramiento y transformación de la valoración de las culturas en originales y subsidiarias o derivadas. Por ende, podría decirse que en los fenómenos de copia se advierten efectos auspiciosos de transmutación y transversalización.

En ese marco, Walcott establece algunos principios de acuerdo y disidencias profundas con el escritor trinitense Naipaul y defiende la disponibilidad a copiar como posibilidad de aprender una destreza, mostrar una habilidad y profundizar el dominio de un oficio. La reivindicación del espejeo intercultural postula así una mirada intersticial entre dos tradiciones decisivas de lecturas del Caribe, que desde posiciones fuertemente enfrentadas concibieron a la pulsión mimética caribeña como una tendencia profundamente negativa. Tal como es posible reconocer en los cuestionamientos que sostiene Naipaul en defensa del racismo y la negación de posibilidad de cultura y arraigo en el Caribe desplegados en la novela 
Los simuladores de 1967, por un lado, así como también, en el cuestionamiento a la racialización y la instrumentalización de los abstractos universales sostenido por la negritud desde el Cuaderno de un retorno al país natal de Aimé Césaire de 1939 en adelante.

Cuando Walcott toma a Vidia Naipaul como referente de su reflexión considera que el insulto disparado sobre las Indias Occidentales contiene alguna verdad que debe ser revisada (Walcott, 2016). Acuerda con el diagnóstico que hace el trinitense acerca de la pantomima conducida por la referencia a las metrópolis que impone la experiencia trágica generada por políticos que, al imitar modelos dominantes sostienen la autoridad de los mercados, pero desconocen la "autoridad desesperada del hombre que no tiene nada" (Walcott, 2016, p. 293). Coincide, además, con Naipaul cuando afirma que cada vez que el escritor caribeño pone una palabra está imitando, fenómeno por el cual aparece la comparación con un simio, cuya autocontemplación es infinita. Sin embargo, el recurso del santalucense es exponer al espejeo como una práctica infatigable que se reproduce infinitamente y al hacerlo propone una invencible fuerza vital. Así destaca:

La frase Los simuladores, que muchos intelectuales angloparlantes de las Indias Occidentales han tomado ávidamente para sí mismos, casi de una forma masoquista, es una invención del novelista indo-occidental Naipaul, que la utiliza como título de una de sus novelas. Su epitafio sobre todo el esfuerzo Indo Occidental no ha terminado con la pasión con la que la cultura de las Indias Occidentales continúa reproduciendo su mimetismo, porque la vida, si podemos llamarla así en el archipiélago, continúa desafiante. (Walcott, 2016, p. 293)

La copia es un recurso de la vida según Walcott, porque constituye una estrategia de supervivencia a nivel de la naturaleza y porque, además, es una estrategia de resistencia a nivel de rituales culturales primordiales en el Caribe. El escritor santalucense ilustra el pasaje de la imitación a la invención a propósito de un instrumento que nace de los desechos, el detritus de la vida social como son las latas de aceites que los antillanos cortan y golpean hasta hacerlas sonar entre el xilofón y el tambor. Y se detendrá en particular en el "steel-pan", instrumento del carnaval de Trinidad que según dice ha nacido en épocas en que el tambor había sido prohibido y demuestra una sutil ampliación de sonidos cada año. Así, señala:

La ceremonia que mejor ejemplifica esta actitud hacia la historia es el ritual del carnaval. Es una forma de arte masivo que salió de la nada, que emergió de las sanciones impuestas. La prohibición de los tambores africanos llevó al descubrimiento de la tapa del tarro de la basura como un potencial instrumento musical, cuya sutil gama, transferida al barril de aceite vacío, aumenta anualmente, y el calipso mismo emergió de un sentido de imitación, de un patrón que está formado de la sátira y la auto-sátira. Los elementos imprevistos del calypso, como la improvisación y la invención de la música de las bandas de acero, sustituye 
sus orígenes tradicionales, es decir, la banda de acero reemplaza el intento de copiar la melodía del xilófono y del tambor, el calypso sustituye sus tradiciones rituales antiguas de canto grupal. Desde el punto de vista de la historia, estas formas se originaron en la imitación, si se quiere, y terminaron en la invención, y esto mismo es cierto para la costumbre del carnaval. (Walcott, 2016, p. 295)

En el disfraz, el steel-pan y el calypso, canción popular del carnaval trinitense que se populariza a comienzos del siglo XX y representa la música callejera multiétnica ligada al mundo de los afrodescendencia (Rohler, 2001), Walcott descubre la posibilidad de mostrar que el fragmento de verdad jugado en la condena de Naipaul debe evaluarse nuevamente. En tanto y en cuanto la pregunta que Naipaul responde negativamente a propósito de si algo puede ser creado en el Caribe y si existe allí un pueblo, se remonta según el mismo Walcott señalaría en un pasaje del texto Las Antillas, fragmentos de una memoria épica (2000) a las perspectivas eurocéntricas formuladas por la historiografía decimonónica de James Anthony Froude.

Walcott revierte en 1974 el texto de Naipaul y la idea colonialista que él reproduce, haciendo reverberar lúdicamente la palabra "nada": abriendo consideraciones en torno del "río inmóvil" o espejo que propone volver a inventar la fuerza del lenguaje o más estrictamente hablando, de una palabra. En tal sentido, afirmará que es verdad que no se crea nada en el Caribe porque nada como en el Caribe puede despertar la inmensidad del asombro y la singularidad que preexisten a cualquier acto de la imaginación y que el poeta hace residir en la belleza del paisaje. Como en otros momentos de su obra caracteriza el lugar haciendo uso de una frase disyuntiva: estar allí es atreverse a elegir entre "la venganza o la nada" y elige la nada. Puntualiza, distingue y enfatiza el valor del vacío productivo y todo aquello que es prácticamente insignificante: el Caribe como un intervalo de notable riqueza cuando el juego especular se transforma en ejercicio paroxístico del espejo que implica ir más allá de fronteras epistémicas. El poder de la imitación desata la interpelación de la idea de descubrimiento y de origen, pero también la idea de cultura original y la idea eurocéntrica de superioridad cultural (Jay, 2006). Walcott (2016) afirma que efectivamente "Nosotros no hemos inventado nada" (p. 297) "pero tampoco Ford ni Edison" puesto que la luz, la electricidad y el auto también son imitaciones de ideas originadas en la naturaleza y en los accidentes de los elementos naturales. La comparación abre nuevamente una fuerte reminicencia con las rutas de escritura de Aimé Césaire. Puesto que cruza una interpelación profunda de la mistificación del progreso con la intensa invocación que abre en uno de sus pasajes el archivo de la memoria negra compuesta por Aimé Césaire, cuando el llamado "padre de la negritud" levanta en un momento del Cahier el valor de la afrodescendencia cuando patentiza la corporeidad de quienes no han inventado nada. Césaire (2000) escribe: 
Los que no han inventado ni la pólvora ni la brújula los que no han sabido domeñar ni el vapor ni la electricidad los que no han explorado ni los mares ni el cielo pero sí saben de todos los rincones del territorio del dolor los que del viaje solo conocen los desarraigos los que se han ablandado de puro arrodillarse los que fueron domesticados y bautizados los que fueron inoculados de bastardía tam-tams de manos vacías tam-tams inanes de llagas sonoras tam-tams burlescos de traiciones tábidas. (p. 60)

Entre la nada como vacío cultural asignado al Caribe por el racismo eurocentrado de Froude que se continúa en Naipaul y la oposición frente a Europa que marca las poéticas de la negritud y algunos de sus legados, Walcott elige el desvío. El poeta santalucense afirma el trazado de descentramientos culturales sucesivos por los que la irrupción de una nueva memoria postula otro destino para algunos imaginarios canónicos occidentales tales como los de la poesía épica, el discurso historiográfico y la mistificación de la superioridad de algunas lenguas. También, postula otro destino respecto de imaginarios propuestos por la literatura caribeña y el pensamiento decolonial. Con notable ironía resguardada en la figura de un oxímoron, el texto concluye señalando que la confianza en la reinvención de las sociedades es efecto de la estupidez superior con que están afectados poetas y satíricos y que, sin pretender hacer ningún alegato de regreso al Edén ni anhelo de construir utopías, el archipiélago americano, es decir el Caribe, es el sitio más fértil para cumplir con esa renovación, aun cuando afirmar tal cuestión pudiera parecer visionario (Walcott, 2016). De tal modo que esa inscripción invoca el valor de lo que no existe todavía, el lugar irreductible de la ficción como fuerza decolonizadora capaz de restituir la fuerza crítica de la imaginación...

\section{Referencias bibliográficas}

Baugh, E. (2012). The West Indian Writer and his Quarrel with History. Small Axe, Año 16.

Caisso, C. (2015). Indigenización en el teatro de Derek Walcott. Amerika. Mémoires, Identités, Territoires. Año 13.

Césaire, A. (2000). Para leer a Aimé Césaire. México: F.C.E.

Fanon, F. (1986). Los condenados de la tierra. México: F.C.E.

Fumagalli, M.C. (2001). The Flight of the Vernacular. Seamus Heaney, Derek Walcott and the Impress of Dante. Amsterdam-New York: Edit. Rodopi.

Glissant, E. (2005). El discurso antillano. Caracas: Monte Ávila Editores. 
James, C.L.R. (2010). Los propietarios. En: Los jacobinos negros. La Habana: Fondo Editorial Casa de las Américas.

Jay, P. (2006). Fated to Unoriginality. The Politics of Mimicry in Derek Walcott's Omeros. Callaloo, Año 29.

King, B. (2004). Derek Walcott and West Indian Drama. New York: Oxford University Press.

Lamming, G. (2010). Los placeres del exilio. La Habana: Fondo Editorial Casa de las Américas.

Rohlehr, G. (2001). The Calypsonian as Artist: Freedom and Responsability. Small Axe. Año 9.

Walcott, D. (1996). El reino del caimito. Bogotá: Grupo Editorial Norma.

Walcott, D. (2000). La voz del crepúsculo. Madrid: Alanza Editorial.

Walcott, D. (2012). Pleno verano. Poesía selecta (1948- 2004). Madrid: Vaso Roto Ediciones.

Walcott, D. (2016). El Caribe ¿cultura o mimetismo? Revista Iberoamericana, Año LXXXII.

Walcott, D. (2017). Otra vida. Barcelona: Galaxia Gutenberg. 